\title{
A Decadal Global Climatology of Ice Cloud Fraction with Their Microphysical and Optical Properties Inferred from the CALIPSO and Reanalysis Data
}

\author{
Honglin Pan ${ }^{1}$, Minzhong Wang ${ }^{1, *}$, Kanike Raghavendra Kumar ${ }^{2,3}{ }^{\circledR}$, Jiantao Zhang ${ }^{1}$ and \\ Lu Meng 1 \\ 1 Taklimakan Desert Meteorology Field Experiment Station of CMA, Institute of Desert Meteorology, \\ China Meteorological Administration (CMA), Urumqi 830002, China; panhl@idm.cn (H.P.); \\ zhangjt@idm.cn (J.Z.); menglu@idm.cn (L.M.) \\ 2 Department of Physics, Koneru Lakshmaiah Education Foundation (KLEF), Vaddeswaram, Guntur, \\ Andhra Pradesh 522502, India; rkkanike@kluniversity.in \\ 3 Collaborative Innovation Centre on Forecast and Evaluation of Meteorological Disaster, \\ Key Laboratory for Aerosol-Cloud-Precipitation of China Meteorological Administration, \\ School of Atmospheric Physics, Nanjing University of Information Science and Technology, \\ Nanjing 210044, China \\ * Correspondence: wangmz@idm.cn
}

Received: 19 October 2020; Accepted: 17 November 2020; Published: 19 November 2020

\begin{abstract}
In the present study, the spatiotemporal and vertical distributions of ice cloud properties and their association with meteorological variables are analyzed for the period 2007-2016 using the Cloud-Aerosol Lidar and Infrared Pathfinder Satellite Observation (CALIPSO) and Modern Era Retrospective-Analysis for Research (MERRA-2) reanalysis observations. The distribution of ice cloud fraction (ICF) with its peak does not overlap with that of the ice water content (IWC) peak during daytime and nighttime due to the sampling bias. Moreover, the vertical distributions of mean IWC exhibited a vaguely "sharp thorn" at an altitude of $\sim 4 \mathrm{~km}$ in all seasons at the location of about $\pm 40^{\circ}$, which can be caused by the artifacts. Furthermore, it is noted that different ice cloud optical depth (ICOD) presents significant changes observed in their diurnal variations in the heights of peaks. The maximum diurnal difference of ice cloud properties occurs in the tropical regions of the North Hemisphere (NH) during summer. We also investigated the relation between ICOD and the meteorological variables and found that the ICOD values are dependent on the meteorological parameters.
\end{abstract}

Keywords: ice cloud properties; spatial and vertical distributions; diurnal changes; CALIPSO

\section{Introduction}

Ice clouds are one of the key regulators of global surface temperature. They have implications for the Earth's radiative balance, hydrological cycle, atmospheric circulation, and climate change owing to their widespread occurrence and long duration [1,2]. The net cooling or warming of ice clouds are impacted by their optical and microphysical properties such as optical depth, water content as well as by macro-physical characteristics of cloud location and coverage throughout the atmosphere [3-5]. However, owing to insufficient knowledge of ice cloud microphysical properties and the complexity of remote-sensing methods, large discrepancies still occur in the scientific understanding of their climatology [6,7]. Moreover, taking the complicated cloud thermodynamic phase transition into account, this contributes to the representation of ice clouds in the climate model remaining uncertain [8-10]. The related studies argued that the climatology of ice clouds obtained from global cloud models (GCMs) 
presents a relatively large difference in spatiotemporal distribution, compared with that retrieved from satellite measurements [11,12].

The vertical distribution of ice clouds plays a pivotal role in determining the ice cloud radiative forcing. Furthermore, compared to horizontally resolved measurements, the vertical measurements of ice clouds properties are insufficient in the globe due to the complexity of sampling. Previous studies have been conducted to analyze the occurrence frequencies of ice clouds as well as their spatiotemporal variability of optical and microphysical properties [13-17]. However, due to the importance and complexity of ice clouds in the atmosphere mentioned above, these studies are not enough. Moreover, many of them were limited to small spatial regions and short temporal period as well as a certain classification of ice clouds. For example, Berry and Mace [18] investigated how ice clouds with ice water path (IWP) of $\sim 20 \mathrm{~g} / \mathrm{m}^{2}$ contribute obvious heating to Earth during the Asia summer monsoon. Tsushima et al. [19] found that the error of the frequency of anvil cirrus in the tropics causes the bias of the cloud radiative effect. Therefore, a long-term and large-scale climatological study of ice clouds is favorable for isolating some specific physical processes, which could be regarded as the source of the biggest cloud model errors.

In the current work, we utilized the Cloud-Aerosol Lidar and Infrared Pathfinder Satellite Observation (CALIPSO) level 3 light detection and ranging (lidar) ice cloud products and its occurrences to investigate the vertical distribution of seasonal and diurnal variations. The ice cloud products, namely, the ice cloud fraction (ICF), the ice water content (IWC), and the ice cloud optical depth (ICOD) globally distributed are obtained for the period 2007-2016. For this, the entire year was divided into four seasons which are considered as spring (March-April-May; MAM), summer (June-July-August; JJA), autumn (September-October-November; SON), and winter (December-January-February; DJF). Also, we analyzed the relationship between the ice cloud parameters and meteorological variables retrieved from the Modern Era Retrospective-Analysis for Research of version 2 (MERRA-2) reanalysis products. The paper is organized into four sections as follows: Section 2 describes the datasets and methods. The results and discussion are given in Sections 3 and 4, respectively; whereas, the summary of conclusions obtained from the study are revealed in Section 5 .

\section{Data and Methods}

\subsection{The Cloud-Aerosol Lidar and Infrared Pathfinder Satellite Observation (CALIPSO)/CALIOP Level-3 Ice Cloud Product}

The newly released (December 2018) level-3 version 1.00 monthly gridded ice cloud datasets are used in the present study from January 2007 to December 2016. The spatial resolutions are $2^{\circ}$ latitude and $2.5^{\circ}$ longitude, and with a vertical resolution of $120 \mathrm{~m}$ ranging from $-0.5 \mathrm{~km}$ to $20.2 \mathrm{~km}$ above the mean sea level (AMSL), generating three different types of profiles (i.e., daytime, nighttime, and combined) depending on the light conditions (specifically for daytime observations of optically thin ice clouds, which can be affected by the noise from sunlight). Moreover, the data files are created from level-2 version 4.10 cloud profile products, which can pass the criteria of quality assurance (QA) and quality control (QC). Detailed information about the dataset and quality filter can be found online at https://www-calipso.larc.nasa.gov/resources/calipso_users_guide/data_summaries/13/lid_13_ice_ cloud_v1-00_v01_desc.php. Liu et al. [20] found that the misidentification of aerosol as cloud occurred by the CALIPSO when the dust or smoke layer is thick, and optical depth becomes similar to the cloud, or if the aerosol is located near the cloud layer. Also, they have pointed out that the misclassification of aerosol under thin ice clouds can be a problem. Consequently, the retrieval errors should be considered when the results from the present study are explained.

We also selected another level 3 version 1.0 cloud occurrence monthly gridded data product with the longitudinal and latitudinal resolutions of $5^{\circ}$ and $2^{\circ}$, respectively, and vertical resolution of $60 \mathrm{~m}$ (different from the level 3 ice cloud product); as well as three files including daytime and nighttime observations, and all representations according to the light conditions. The ICOD histogram with six levels of optical depth was utilized in this dataset. Using the daytime and nighttime files, 
the diurnal variations of the vertical distribution of ICF, IWC, and ICOD were inspected by analyzing the night-minus-day measurements.

Also, the CALIPSO level 3 ice cloud product provides the meteorological context, including temperature and relative humidity. It is noted that the products are interpolated to each CALIPSO bin (latitude/longitude/altitude), making two variables with the same resolution to ice cloud variables, derived from the MERRA-2 reanalysis product.

\subsection{Methodology}

Based on the primary variables (sampling counts) in the CALIOP dataset, we estimate the ICF in the zonal distribution based on Equation (1) given below:

$$
I C F_{\text {zonal }}=\frac{\sum_{\text {long }=-178.75^{\circ}}^{178.5^{\circ}}(\text { ICAS })}{\sum_{\text {long }=-178.75^{\circ}}^{178}(C S+C F S)}
$$

here, CS, CFS, ICAS refers to the number of cloud samples, the number of cloud-free samples (clear sky or aerosol features), and the number of ice cloud-accepted samples (amount of ice cloud samples passed the quality filters including QA and QC, e.g., choosing clouds with CAD (cloud-aerosol-discrimination) score between 20 and 100, and only randomly oriented ice clouds with high confidence are considered. As well as this, only extinction, QC flag $=0,1,2,16$, or 18 are allowed from the $532 \mathrm{~nm}$ channel, respectively. The latitudinal ICF describes the cloud fraction as a function of latitude and height, which requires integration over longitudinal samples (for brevity denoted as "long," ranging from $-178.75^{\circ}$ to $178.75^{\circ}$ ) for each latitude and height bin.

Furthermore, we have calculated the zonal distribution of the IWC based on Equation (2) shown below:

$$
I W C_{\text {zonal }}=\frac{\sum_{\text {long }=-178.75^{\circ}}^{178.75^{\circ}} \bullet\left(\sum_{\text {bin=2 }}^{16} I W C B B \times I W C H+\sum_{\text {bin }=19}^{43} I W C B B \times I W C H\right)}{\sum_{\text {long }=-178.75^{\circ}}^{178.75^{\circ}}(C S+C F S)}
$$

here, IWCBB (IWC boundary bin) represents 44 bins of the full distribution of the IWC, and we excluded the small and large outliers in bins 1 and 44, as well as low magnitude values with less confidence in bin 17 and 18 to obtain the reasonable results. IWCH (IWC histogram) refers to the histogram of the IWC. Similarly, CS, CFS are defined as the number of cloud samples, number of cloud-free samples (clear sky or aerosol features), respectively. Individually, the cloud occurrence is considered in the denominator. Therefore, the equation derives the gridded-averaged IWC. The detailed information about the formula can be found online at https://www-calipso.larc.nasa.gov/resources/calipso_users_ guide/qs/cal_lid_13_ice_cloud_v1-00.php.

\section{Results}

\subsection{Seasonal Zonal Altitude Distributions of Ice Cloud Fraction (ICF)}

In this section, we discuss the zonal altitude distributions of a 10-year mean of ICF distributed over four seasons, based on Equation (1). As shown in Figure 1, the coverage of ICF generally exhibited a vertical distribution with a single peak, and the flattened top can be caused by the strong mixing (e.g., temperature, water vapor) and heat transport by Hadley circulations between $\pm 30^{\circ}$. The peak is below the tropical tropopause (displayed in black solid line, and the data also originated from the level 3 product), and decreasing in altitude steadily towards both the South Hemisphere (SH) and North Hemisphere $(\mathrm{NH})$ polar regions, which can be related to the general circulation height (i.e., Hadley, Ferrel, and Polar cell). In the summer, the maximum ICF of $\sim 40 \%$ occurred at the latitude of $0-20^{\circ}$ over the $\mathrm{NH}$, and ice clouds can reach higher altitudes towards the north of the equator than the south. Meanwhile, the opposite phenomena were observed in the winter period attributed 
to the vigorous convective activity in tropical areas, the distributional variation of land and ocean over the $\mathrm{NH}$ and $\mathrm{SH}$, and the seasonal migration in the position of the inter-tropical convergence zone (ITCZ). These results are consistent with that reported by Huang et al. [21] and Su et al. [22]. Also, the polar stratospheric clouds (PSCs) were observed in the SH during the summer and autumn seasons. Moreover, the availability of the CALIOP nighttime data during the summer season in the high latitudes of NH is limited, as revealed in Figure 1. The same has been observed and reported by Anderson et al. [23], due to the two facts that daytime is longer than nighttime in the summer season over the high latitudes of NH, and observations during nighttime are decreased. However, the opposite is found in the SH polar area. It has to be noted that we used the arithmetic mean to compute the annual distribution of ICF.
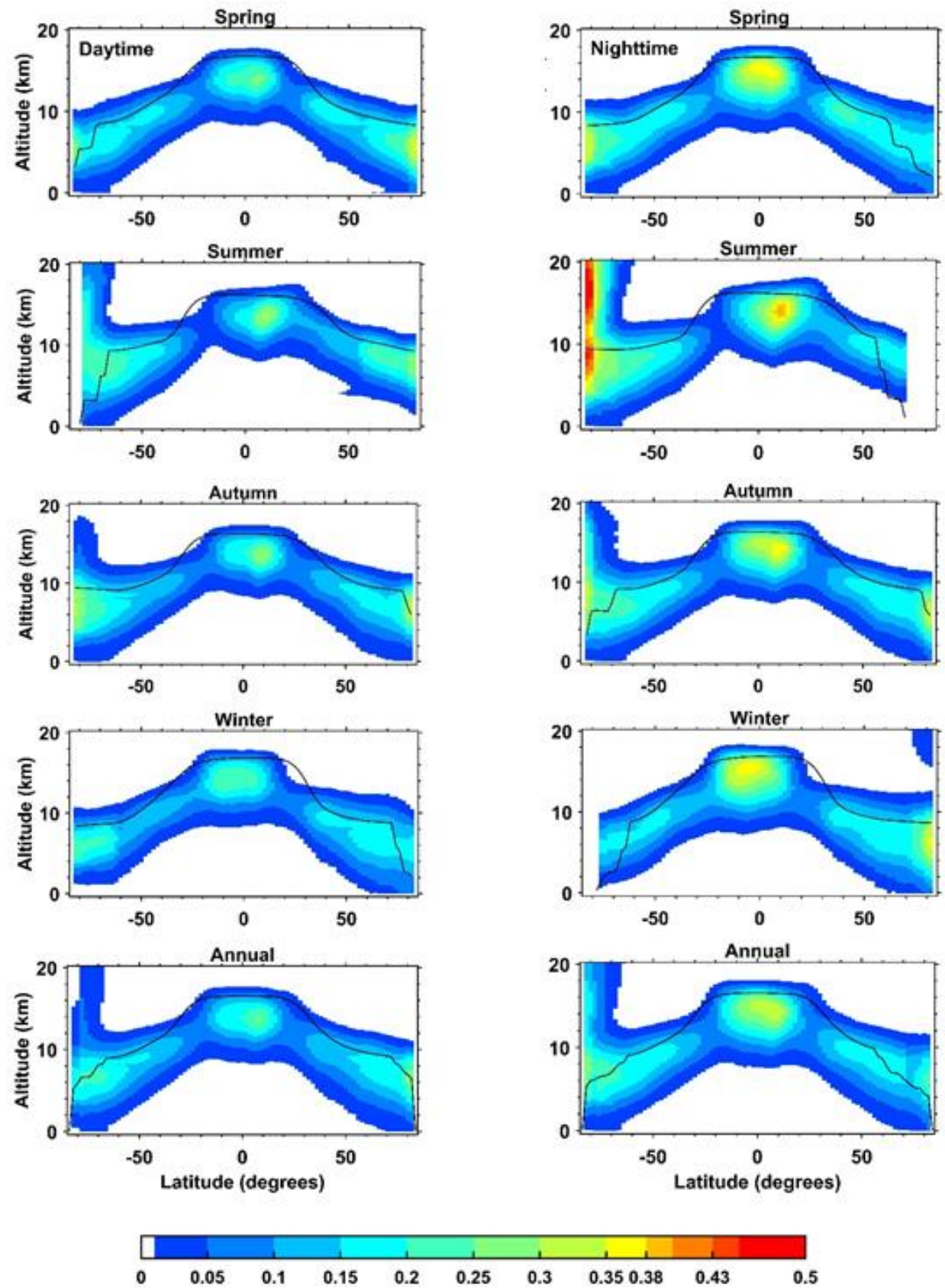

Figure 1. Seasonal and annual distributions of the 10-year mean ice cloud fraction (ICF) over latitude during the daytime (left panels) and nighttime (right panels) for four seasons observed from the CALIOP. The white color represents the value of less than 0.01 . The solid black line refers to tropopause height. 
As presented in Table 1, we found that the seasonal and annual mean ICF during the nighttime is larger than of the daytime. For instance, the annual mean of ICF is about 0.40 in the nighttime, but it is about 0.31 during the daytime. The same can be explained as the signal-to-noise ratio declines from the influence of the solar background during the nighttime. The minima, maxima, and mean of the ICF observed during daytime and nighttime for four seasons over the globe are listed in Table 1.

Table 1. The minimum, maximum, and mean of ICF observed from the Cloud-Aerosol Lidar and Infrared Pathfinder Satellite Observation (CALIPSO) during daytime and nighttime in four seasons over the globe between 2007 and 2016.

\begin{tabular}{ccccccc}
\hline \multirow{2}{*}{ Season } & \multicolumn{7}{c}{ Daytime Nighttime } \\
\cline { 2 - 7 } & Minimum & Maximum & Mean & Minimum & Maximum & Mean \\
\hline Spring & $<0.01$ & 0.35 & 0.06 & $<0.01$ & 0.37 & 0.07 \\
Summer & $<0.01$ & 0.31 & 0.05 & $<0.01$ & 0.48 & 0.08 \\
Autumn & $<0.01$ & 0.32 & 0.05 & $<0.01$ & 0.38 & 0.07 \\
Winter & $<0.01$ & 0.25 & 0.05 & $<0.01$ & 0.37 & 0.07 \\
Annual & $<0.01$ & 0.31 & 0.05 & $<0.01$ & 0.40 & 0.07 \\
\hline
\end{tabular}

\subsection{Seasonal Zonal Altitude Distributions of Ice Water Content (IWC)}

The zonal altitude distributions of the 10-year mean CALIOP observations of IWC illustrated in Figure 2 revealed asymmetrical distributions. However, the distribution of the ICF peak does not overlap with that of the IWC peak during daytime and nighttime due to the sampling bias. Namely, more (less) samples of IWC in a large bin of 19-43 (small bin of 2-16) were found in the daytime than nighttime. That is, the lower (higher) IWC values have more (less) samples during the nighttime than daytime, respectively (see Figure 3). Meanwhile, the zonal altitude distributions of IWC showed a vaguely "sharp thorn" at an altitude of $\sim 4 \mathrm{~km}$ for all the seasons at the location of $\pm 40^{\circ}$ (Figure 2). The same can be explained as the artifacts because the IWC retrievals are calculated as a simple parameterized function of Equation (3) stated below, where $\sigma$ is the volume extinction coefficient at $532 \mathrm{~nm}$ in $\mathrm{km}^{-1}$, and $\mathrm{C}_{0}=119 \mathrm{~g} \cdot \mathrm{cm}^{-3}$ and $\mathrm{C}_{1}=1.22$ are parameters obtained from an observed empirical relationship between lidar extinction and in situ measurements of cloud properties $[24,25]$. Consequently, in-depth analysis and more validations should be performed to explore this discrepancy further.

$$
I W C=C_{0}\left(\frac{\sigma}{1000}\right)^{C_{1}}
$$

As revealed in Table 2, the seasonal and annual IWC during the nighttime is smaller than in the daytime. For example, the annual mean of IWC is about $0.00094 \mathrm{~g} / \mathrm{m}^{3}$ during nighttime, but the daytime is about $0.0011 \mathrm{~g} / \mathrm{m}^{3}$. The detailed summary (including the minima, maxima, and mean) of the IWC data observed in four seasons is tabulated in Table 2. Noticeably, we excluded the outliers of the IWC (in Figure 2, the small red rectangle contains one IWC data over the $\mathrm{SH}$ polar region in summer, the big red rectangle zooms in on the little red rectangle) because of the value larger than $0.01 \mathrm{~g} / \mathrm{m}^{3}$. 

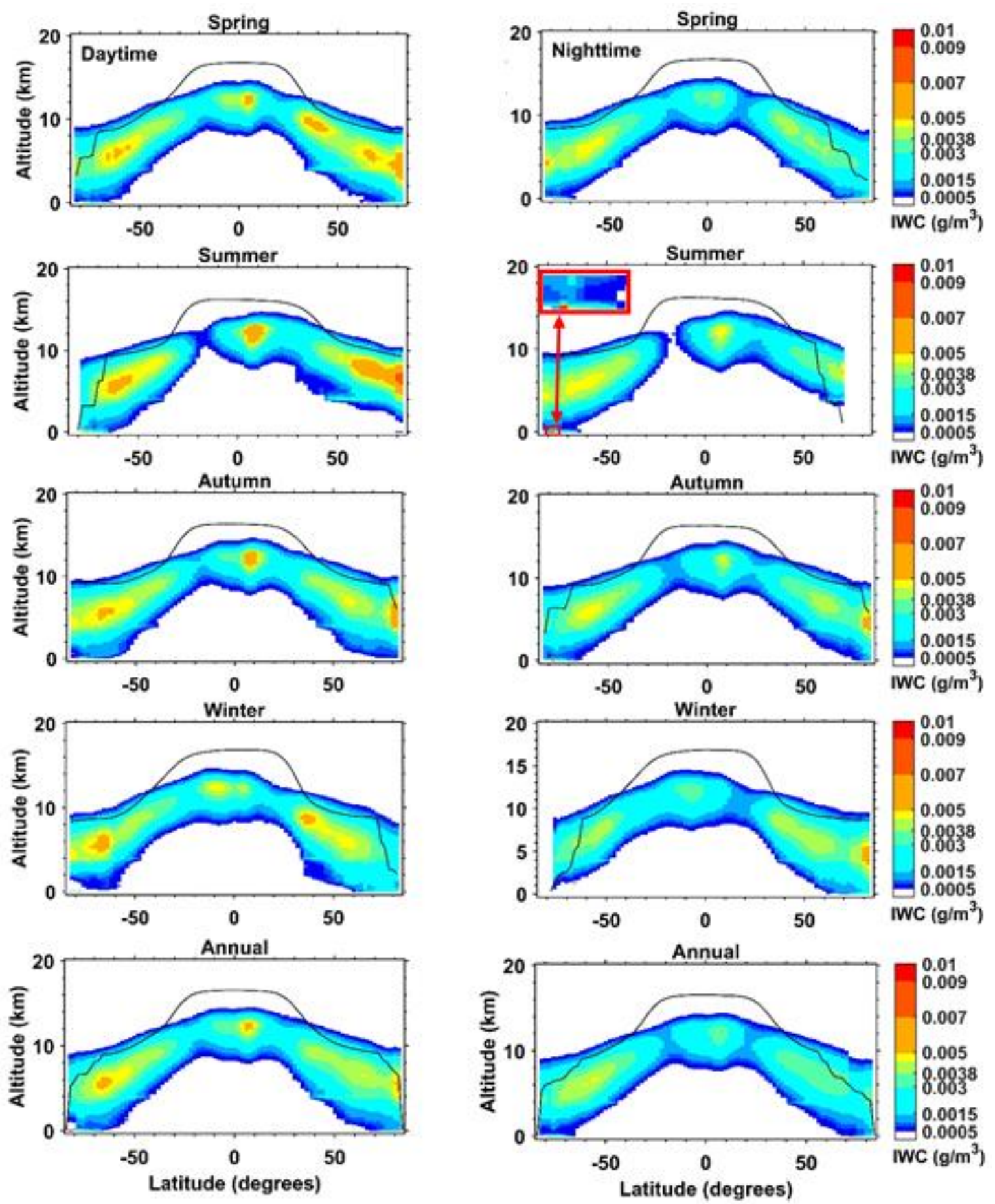

Figure 2. Same as in Figure 1, but for the ice water content (IWC). The white color represents the value of less than $0.0005 \mathrm{~g} / \mathrm{m}^{3}$. 


\begin{tabular}{|l|l|l|}
\hline Bin Number & Extinction Coefficient Range $\left(\mathrm{km}^{-1}\right)$ & IWC Range $\left(\mathrm{g} \cdot \mathrm{m}^{-3}\right)$ \\
\hline 1 & $\left(-3.402 \times 10^{38},-1.0 \times 10^{-1}\right)$ & $\left(-3.402 \times 10^{38},-1.0 \times 10^{-2}\right)$ \\
\hline $\mathbf{2 - 1 6}$ & {$\left[-1.0 \times 10^{-1},-1.0 \times 10^{-4}\right)$} & {$\left[-\mathbf{1 . 0} \times \mathbf{1 0} \mathbf{0}^{-\mathbf{2}}, \mathbf{- 1 . 0 \times 1 0 ^ { - 5 }}\right)$} \\
\hline 17 & {$\left[-1.0 \times 10^{-4}, 0\right)$} & {$\left[-1.0 \times 10^{-5}, 0\right)$} \\
\hline 18 & {$\left[0,1.0 \times 10^{-4}\right)$} & {$\left[0,1.0 \times 10^{-5}\right)$} \\
\hline $\mathbf{1 9 - 4 3}$ & {$\left[1.0 \times 10^{-4}, 1.0 \times 10^{+1}\right)$} & {$\left[\mathbf{1 . 0 \times 1 0 ^ { - 5 }}, \mathbf{1 . 0 \times 1 0 ^ { 0 }}\right)$} \\
\hline 44 & {$\left[1.0 \times 10^{+1}, 3.402 \times 10^{38}\right)$} & {$\left[1.0 \times 10^{0}, 3.402 \times 10^{38}\right)$} \\
\hline
\end{tabular}
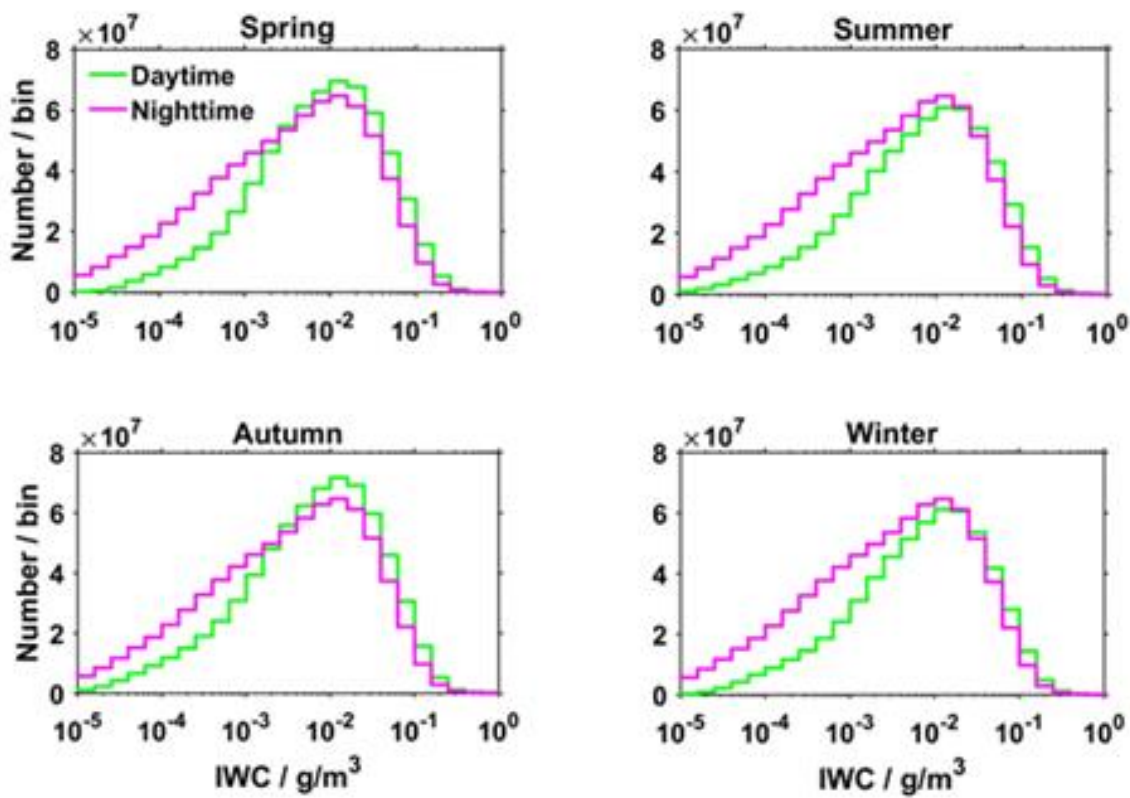

Figure 3. The top panel is the histogram bin range of IWC (red box) and extinction coefficient. The bottom panels show histograms of IWC derived from the 10-year measurements of the CALIOP for four seasons.

Table 2. Same as in Table 1, but for IWC. The unit of IWC is $\mathrm{g} / \mathrm{m}^{3}$.

\begin{tabular}{ccccccc}
\hline \multirow{2}{*}{ Season } & \multicolumn{7}{c}{ Daytime Nighttime } \\
\cline { 2 - 7 } & Minimum & Maximum & Mean & Minimum & Maximum & Mean \\
\hline Spring & $<0.00001$ & 0.00660 & 0.00120 & $<0.00001$ & 0.00890 & 0.00096 \\
Summer & $<0.00001$ & 0.00740 & 0.00110 & $<0.00001$ & 0.01530 & 0.00087 \\
Autumn & $<0.00001$ & 0.01300 & 0.00110 & $<0.00001$ & 0.01230 & 0.00095 \\
Winter & $<0.00001$ & 0.00550 & 0.00110 & $<0.00001$ & 0.00560 & 0.00099 \\
Annual & $<0.00001$ & 0.00810 & 0.00110 & $<0.00001$ & 0.01050 & 0.00094 \\
\hline
\end{tabular}

\subsection{Mean Profiles of Diurnal Variations of ICF and IWC}

Based on the daytime and nighttime files of the CALIPSO level-3 data, we used "nighttime minus daytime" measured data to explore the diurnal variations of mean profiles of ICF and IWC for different latitudinal bands. Here, we focused on the boreal summer data, which exhibited more substantial differences between nighttime and daytime. Moreover, considering that these parameters can be affected by pollution near the Earth's surface [9,26-28], and for the following analysis, we select only sampled data higher than $2 \mathrm{~km}$. The results of the analysis are shown in Figure 4, including the diurnal variations and the overall number of samples of ICF and IWC. 

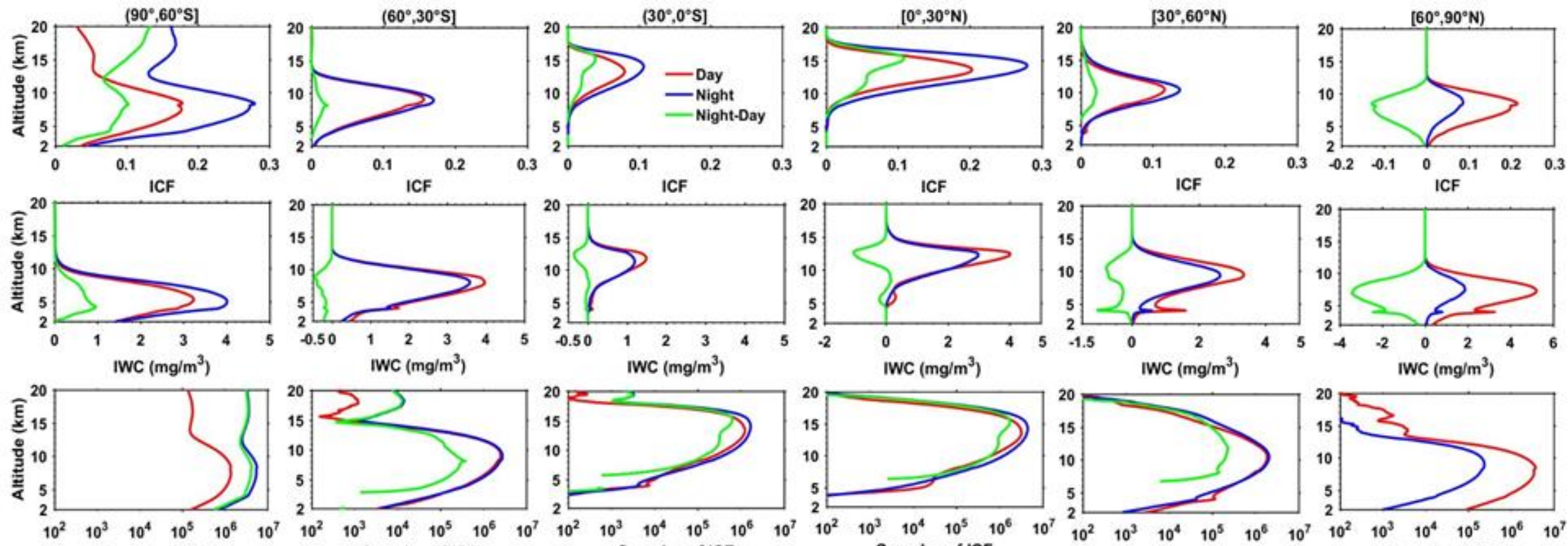

IWC $\left(\mathrm{mg} / \mathrm{m}^{3}\right)$

IWC $\left(\mathrm{mg} / \mathrm{m}^{3}\right)$

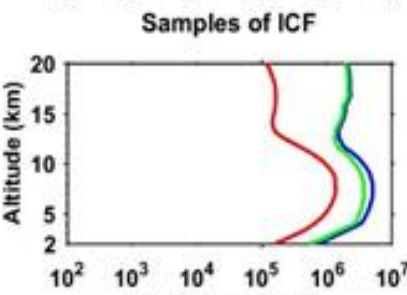

Samples of ICF

Samples of ICF
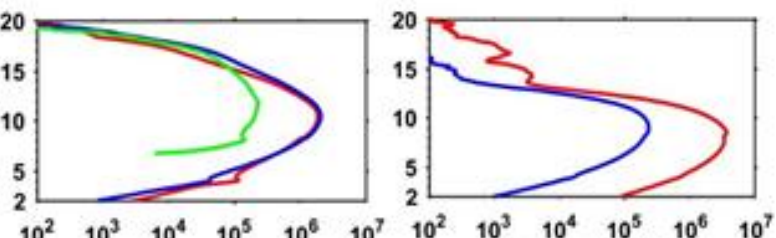

Samples of ICF
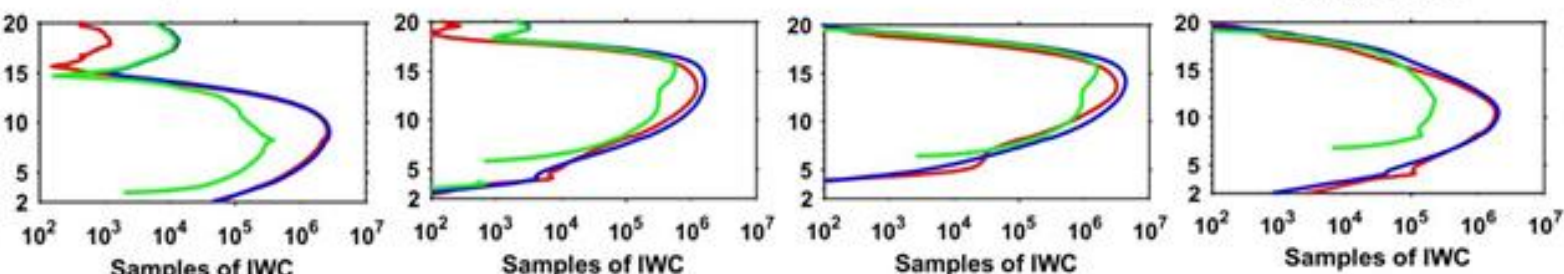

Samples of ICF

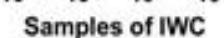

Samples of IWC

Samples of IWC

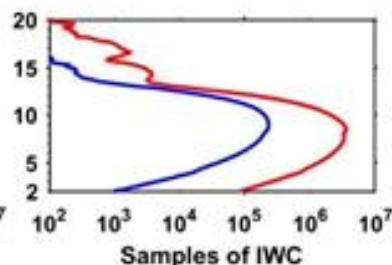

Figure 4. Diurnal variations (night-minus-day measurements) of zonal mean profiles of the frequency of occurrences of ICF and IWC (the first and second rows), vertical patterns of a 10-year total number of ICF and IWC samples (the third and fourth rows). 
Over the SH tropics $\left(30^{\circ}, 0^{\circ} \mathrm{S}\right]$, the diurnal variability of ICF exhibited two peaks at $\sim 10 \mathrm{~km}$ and $\sim 15 \mathrm{~km}$. However, a stronger variation of 0.1 over the $\mathrm{NH}$ tropics $\left[0^{\circ}, 30^{\circ} \mathrm{N}\right)$ was found at the same height. Over the SH mid-latitudes $\left(60^{\circ}, 30^{\circ} \mathrm{S}\right]$, the diurnal difference of ICF peaks was found at $\sim 8 \mathrm{~km}$. A difference between the daily variations of ICF peaks at $\sim 10 \mathrm{~km}$ in the $\mathrm{NH}$ mid-latitude $\left[30^{\circ}, 60^{\circ} \mathrm{N}\right.$ ) and the negative values of ICF was found below $\sim 5 \mathrm{~km}$. In the high-latitude $\mathrm{SH}$ region $\left(90^{\circ}, 60^{\circ} \mathrm{S}\right]$, the ICF exhibited more considerable variation of 0.1 at $\sim 8 \mathrm{~km}$, due to the higher occurrence frequency of PSCs. Conversely, in the high-latitude $\mathrm{NH}$ region $\left[60^{\circ}, 90^{\circ} \mathrm{N}\right)$, the ICF variation at an altitude of $\sim 8 \mathrm{~km}$ is smaller than $\sim 0.1$, attributed to the limited nighttime data (by CALIOP) in the NH high-latitude region. For IWC, the peak altitudes of diurnal variability decrease gradually at low, medium, and high latitude belts for both the hemispheres, which can be attributed to the general circulation height. A more substantial variation (negative trend) occurred in the $\mathrm{NH}$ compared to $\mathrm{SH}$ (due to the difference in land and ocean surface in both the hemispheres and the heat capacity is lower for land so the temperature changes more rapidly). Moreover, we found that the total number of IWC and ICF samples showed a similar distribution during nighttime and daytime, which can further verify the negative diurnal variation of IWC due to larger values in the sampled days (Figure 3). Interestingly, the total number of samples occurred over the low and middle latitude regions below $\sim 5 \mathrm{~km}$ for both the hemispheres found more in the daytime than nighttime (because the $x$-axis is on the logarithmic scale and hence, the negative values were neglected). The same can be explained from the low-level jet streams, which has an obvious diurnal variation, contributing to the decrease in ice cloud samples [29].

\subsection{Spatial and Seasonal Occurrence Frequency of Ice Cloud Optical Depth (ICOD)}

The geographical and seasonal average occurrence frequencies of three types of ICOD or six sub-types over the globe is shown in Figure 5. The three categories of ICOD are sub-visual (ICOD $<0.01$, $0.01 \leq \mathrm{ICOD}<0.03)$, thin $(0.03 \leq \mathrm{ICOD}<0.10,0.10 \leq \mathrm{ICOD}<0.30)$, and opaque $(0.30 \leq \mathrm{ICOD}<1$, ICOD $\geq 1$ ), based on the classification of Sassen et al. [30] and Hong et al. [3], respectively. For sub-visual ice clouds, which present infrequent occurrence in the tropics and less than 0.05 elsewhere, as well as one exception in the SH polar areas, the sub-visual ice clouds are detected during summer. Additionally, ice clouds with $0.01 \leq$ ICOD $<0.03$ are close to zero in the mid-latitudes, and the tropics and high-latitude regions with higher frequency. For thin ice clouds, on the one aspect, they show a larger occurrence in ocean areas than land areas. On the other aspect, the denser concentration can be found in the tropics compared to other areas. For ice clouds with ICOD $\geq 1$, the lower occurrence frequency occurs in the tropics. Conversely, the higher occurrence can be shown in the mid-latitudes, which is following the active storm activities in this region [12]. 

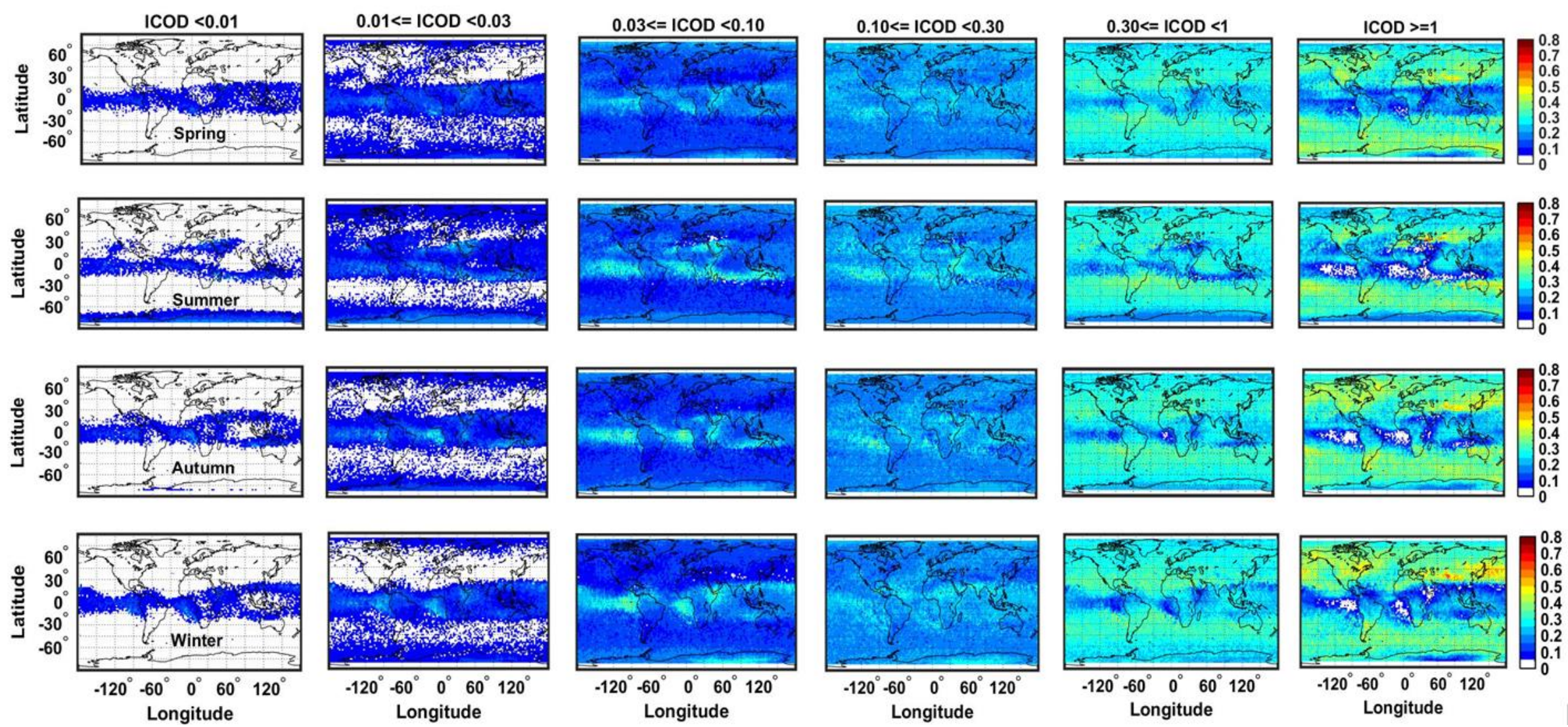

Figure 5. Spatial and seasonal occurrence frequency of ice cloud optical depth (ICOD) with six ranges based on the CALIOP 10-year measurements (day plus night). The white color represents a value of less than 0.05 . 


\subsection{Diurnal Variations of Occurrence Frequency of ICOD}

In this section, we have quantified the occurrence frequency as the ratio of several ICOD samples in a certain category to the overall number of samples (sum of the six sub-groups of ICOD after data screening mentioned in Section 2); and this quantification was performed for each vertical layer. In the following study, we have only considered the boreal summer season to illustrate the diurnal variability of each ICOD, with obvious seasonal variations.

In the first and second panels of Figure 6, the ICOD category of occurrence frequencies steadily increases as ICOD increases for ICOD $<1$ between at an altitude less than $15 \mathrm{~km}$ and about 8 to $11 \mathrm{~km}$. Below $\sim 8 \mathrm{~km}$, the ICOD $>1$ category dominates. By contrast, the occurrence frequency is inversely proportional to the value of all ICOD above the cutoff. As shown in the third panels of Figure 6, we observed that sub-visual ice clouds (ICOD $<0.01$ and $0.01 \leq$ ICOD $<0.03$ ) with larger negative diurnal differences at high-level layers (above $\sim 15 \mathrm{~km}$ ), and maximum difference over the NH tropics. The same has been evident and found in the works of Martins et al. [31]. Conversely, opaque $(0.3 \leq \mathrm{ICOD}<1$ and ICOD $\geq 1)$ ) ice clouds at low-level layers (below $\sim 5 \mathrm{~km})$ showed more significant discrepancy, especially for ICOD $\geq 1$ over the low and mid-latitude belts. Thin ice clouds $(0.03 \leq \mathrm{ICOD}<0.3)$ exhibited small diurnal variations at all altitudes and heights. Also, ice clouds with ICOD $\geq 1$ present positive diurnal variation in all latitude bands. In the fourth panel of Figure 6, the difference between nighttime and daytime (Night-Day) samples showed similar and consistent distributions as observed in Figure 4; namely, more samples during the nighttime relative to daytime due to sunlight contamination in the day resulting in distortion of time signals [32-35]. Except for the latitude $\left[60^{\circ}, 90^{\circ}\right)$ in the fourth panel, there is no data because the $x$-axis is on the logarithmic scale and hence, the negative values are neglected.

Given the sunlight-related noise in the daytime, optically thin layers of ice clouds cannot be probed by the CALIOP compared with the nighttime. Furthermore, the classification into liquid and ice phases of clouds are also affected; that is, more noise during the daytime may more negatively affect the classification of cloud types or clouds and aerosols, compared during the nighttime. Consequently, the artificial daily variations of ice clouds (e.g., classification-induced, instrumentation-induced, and sampling-induced variabilities) should not be neglected. 

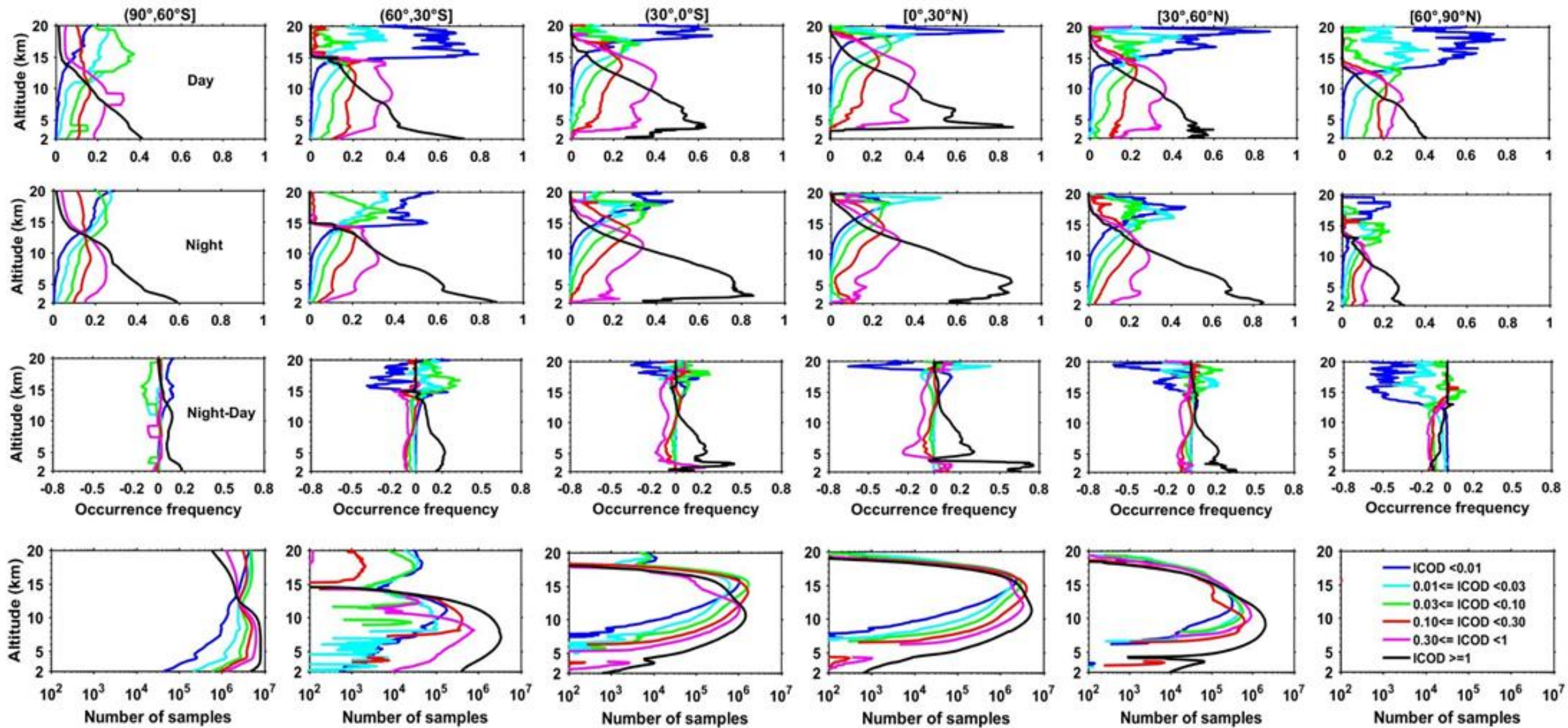

Figure 6. Day and Night observations of zonal mean profiles of the frequency of occurrences of ICOD over six groups (the first and second rows), Diurnal variation (Night-Day) of the frequency of occurrence profiles, and total number samples of ICOD over six groups (the third and fourth rows), obtained from the 10-year CALIOP summertime measurements. 


\subsection{Relationships between Meteorological Variables and IWC, and ICOD}

The aforementioned analyses have concluded the climatology of the seasonal and geographical distribution of IWC and ICOD with six sub-groups and their vertical profiles of diurnal variability over the different zonal bands. Below, we investigate the relationship between meteorological conditions and microphysical and optical properties of ice clouds. Here, we only select summertime to analyze, and two meteorological parameters are utilized including relative humidity $(\mathrm{RH})$ and temperature (TE), which are obtained from the MERRA-2 reanalysis product.

Figure 7 demonstrates the 10-year global distribution of contour density plots between IWC and $\mathrm{RH}$ and TE during nighttime and daytime, respectively. Generally, the data points (N) are relatively less in the night than day, which is attributed to the restriction of data availability detected by the CALIOP during nighttime. We also study the relationship between IWC and RH, which presents the values of IWC peaks at the range of $0.9 \sim 2.7 \mathrm{mg} / \mathrm{m}^{3}$ in the comparatively low $\mathrm{RH}$ of approximately a 36 39\% regime. During the nighttime, IWC peaks at the smaller interval between $0.28 \mathrm{mg} / \mathrm{m}^{3}$ and $1.4 \mathrm{mg} / \mathrm{m}^{3}$ in the $\mathrm{RH}$ with a bigger range from $36 \%$ to $42 \%$ than that daytime. Furthermore, data points of IWC and RH spread towards bigger value during nighttime than daytime. That can be interpreted as more noise from background sunlight during daytime than nighttime, leading to fewer samples being detected from CALIOP in the daytime. Additionally, deep convection activities occur more frequently at night than day, which can transport much more ice cloud (especially for little ice crystals) into high altitude, and contribute to values (IWC and $\mathrm{RH}$ ) with the broader range during the night. For TE and IWC, IWC peaks at the range of $0 \sim 1.98 \mathrm{mg} / \mathrm{m}^{3}$ in the cold $\left(-34^{\circ} \sim-32^{\circ}\right)$ TE regime. At night, IWC peaks at the smaller interval compared to that daytime, between $0 \mathrm{mg} / \mathrm{m}^{3}$ and $1.4 \mathrm{mg} / \mathrm{m}^{3}$ in the TE with the range from $-34^{\circ}$ to $-32^{\circ}$. Likewise, data points of IWC/TE spread towards bigger/lower value during nighttime than daytime.

Next, we also analyze the relationship between meteorological parameters (RH and TE) and occurrence frequencies of ICOD with six sub-categories, and the results are presented in the form of contour density plots are shown in Figure 8. Overall, ICOD for six groups peaks in the same range of $\mathrm{RH}$ and TE in the daytime or nighttime, respectively. However, the magnitudes are different during daytime and nighttime, and data points are more dispersed at night. That can be due to ice clouds being mainly formed at the height of the upper troposphere, and sampling bias owing to much more noise in the daytime, as well as frequent convective activity and precipitation during nighttime. 

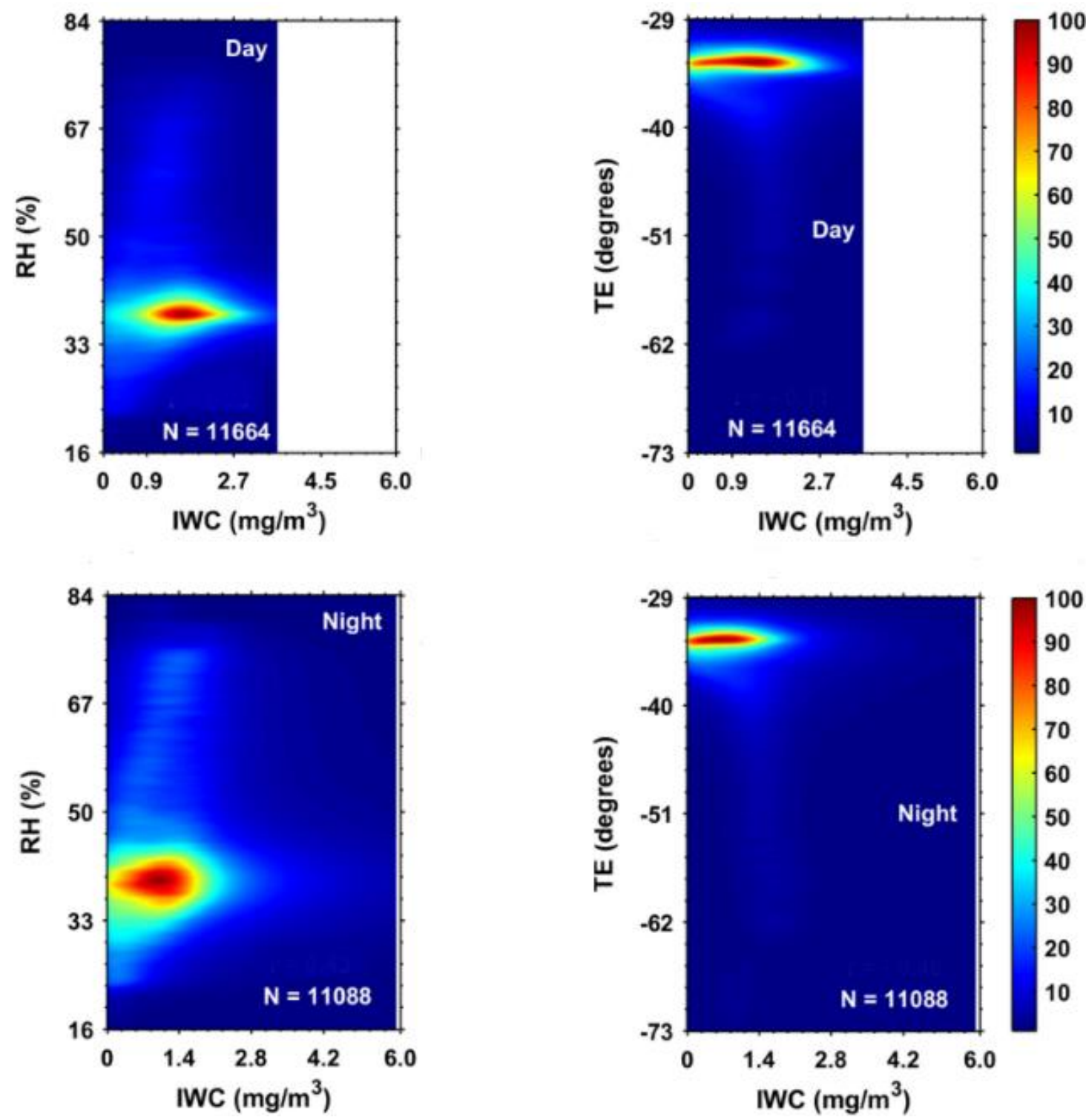

Figure 7. Relationships between average IWC and relative humidity ( $\mathrm{RH}$, left column) and temperature (TE, right column) during day and night in the globe based on the 10-year summertime measurements of CALIOP. The color bar represents the density of data distribution, and the white colors show no data. 

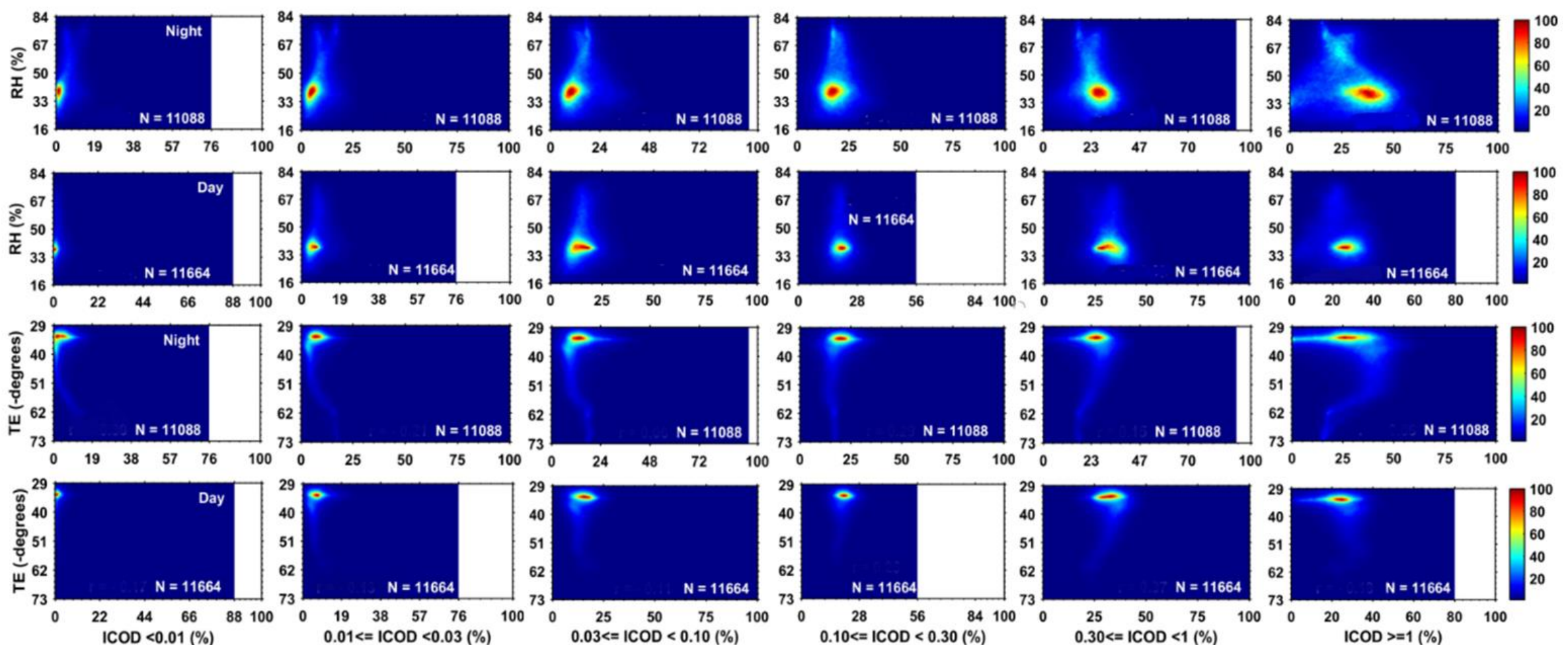

Figure 8. Relationships between occurrence frequency of different ICOD and average RH (first and second row) and TE (third and fourth row) during nighttime and daytime in the globe derived from the 10-year summertime measurements of CALIOP. The percentage (\%) refers to the unit of ICOD on the $x$-axis. The color bar represents the density of data distributions, and the white colors show no data. 


\section{Discussion}

Our results are compared and found in good agreement with the previous studies. Huang et al. [21] used the CALIOP and CloudSat cloud data to investigate the climatology of cloud water content with different cloud types. They revealed that each type of cloud showed an asymmetric distribution over the $\mathrm{NH}$ and $\mathrm{SH}$ areas. Over the mid and high latitudes, clouds present larger seasonal variations in the $\mathrm{NH}$ than $\mathrm{SH}$. The vertical distributions of ICF and IWC presented similar characteristics during the study period. However, we also found that PSCs occurred in the SH. Sassen et al. [27] illustrated the maximum difference of cirrus occurrence over the tropics during the diurnal cycle. Our analysis shown in Figure 1 confirms the same point as their results. Hong and Liu [12] suggested that thin ice clouds frequently occurred in the tropics at high altitudes and not the occurrence of sub-visual ice clouds. Our study indicates that the sub-visual ice clouds are more frequent at high elevations (above $15 \mathrm{~km}$ ) than low altitudes, and regular occurrence of thin ice clouds in the low and middle latitudes at high altitudes. Also, Martins et al. [31] revealed the sub-visual ice cloud showed the maximum occurrence frequency at $\sim 15 \mathrm{~km}$ over the tropics, but at $\sim 10 \mathrm{~km}$ over mid-latitudes. Moreover, they showed that the sub-visual ice clouds with about $30-40 \%$ of ICF are in the strong convective areas, which are consistent with our results shown in Figure 6. We further demonstrated sub-visual ice clouds with the maximum concurrence at $\sim 15 \mathrm{~km}$ over the mid-latitudes by CALIOP data.

It is worth noting that some caveats exist when using the CALIOP level-3 version 1.0 profile product. For example, the polar-orbiting satellite data with a repeat cycle of 16 days and local equator-crossing times (EXTs) of 1:30 a.m./p.m. [36,37], are limited to analyze the diurnal variability of ice cloud properties. However, current climate models cannot accurately depict the vertical distribution of ice clouds, especially on the diurnal difference on the vertical resolving scale. CALIOP does provide a valuable opportunity to study the diurnal variations of the global ice cloud properties.

\section{Conclusions}

In this study, we conducted a statistical analysis of climatology of global ice clouds properties, including ICF, IWC, and ICOD with six sub-categories based on the 10-year (2007-2016) measurements from CALIPSO lidar observed at $532 \mathrm{~nm}$. Moreover, the vertical profiles of diurnal variability (nighttime-minus-daytime measurements) of ice clouds properties were investigated, and their relationships with two variables (RH and TE) were also derived from the MERRA-2 reanalysis product. The seasonal zonal altitude distributions of ICF generally exhibited flattened cosine curve distribution and the peak below the tropical tropopause, and the altitude of ICF was consistent with the overall circulation height in both hemispheres during daytime and nighttime for all the seasons. Over the mid-latitude regions, the occurrence frequency of ice clouds was relatively high during day and night, due to frequent storm activities. For the SH high-latitude region, the rate of ice clouds was relatively high, attributed to the selective capture of PSCs, owing to the sensitivity specifications of the CALIOP. Moreover, we found the global 10-year mean of nighttime data (including IWC and ICF) collected by the CALIOP during the summertime suffered from limited data availability in high-latitude regions over the NH. The vertical distributions of a 10-year mean IWC exhibited a "sharp thorn" at the height of $\sim 4 \mathrm{~km}$ in all seasons at the location of $\pm 40^{\circ}$, which can be caused by artifacts. Also, the maximum diurnal difference of ice cloud properties occurred in the $\mathrm{NH}$ tropics during the summertime. The altitude of the maximum diurnal variation of ICF and IWC decreased as the latitude increased. The magnitudes of the diurnal difference of the ICF and IWC were more extensive in the $\mathrm{NH}$ than $\mathrm{SH}$. The negative night minus day IWC difference was generally observed for all of the considered altitudes due to the IWC having larger values during the day. Moreover, sub-visual ice clouds (ICOD $<0.01$ and $0.01=$ ICOD $<0.03$ ) exhibited larger negative diurnal differences at high-level layers (above $\sim 15 \mathrm{~km}$ ). However, opaque $(0.3 \leq \mathrm{ICOD}<1$ and ICOD $\geq 1)$ ice clouds at low-level layers (below $\sim 5 \mathrm{~km})$ showed a more considerable discrepancy. The ICOD values were dependent on the meteorological parameters (TE and RH). In future work, we can also utilize the CloudSat level 3 product to analyze the climatology 
of liquid clouds, and use the new products of CALIPSO and CloudSat for ice crystal concentrations by Sourdeval et al. [38], which could help to extend the present study.

Author Contributions: Conceptualization, M.W. and K.R.K.; methodology, H.P.; software, J.Z.; validation, H.P., M.W. and K.R.K.; formal analysis, L.M.; investigation, H.P.; writing-original draft preparation, H.P.; writing-review and editing, K.R.K. and M.W.; visualization, H.P., J.Z. and L.M.; supervision, M.W. and K.R.K.; project administration, M.W. All authors have read and agreed to the published version of the manuscript.

Funding: This research was funded by the Strategic Priority Research Program of the Chinese Academy of Sciences (Grant No. XDA20100306), the National Natural Science Foundation of China (Grant Nos. 41775030, 42005074), the Flexible Talents Introducing Project of Xinjiang for the year 2017-2018, the Start-Up Research Grant (SRG) (File No. SRG/2020/001445) sponsored by the Science and Engineering Research Board of the Department of Science and Technology (DST-SERB), India, and Xinjiang Tianshan Youth Program (Grant No. 2017Q042). One of the authors, KRK, is grateful to the DST, Govt. of India, for the award of the DST-FIST Level-1 (Grant No. SR/FST/PS-1/2018/35) scheme to the Department of Physics, KLEF.

Acknowledgments: We are also grateful to the CALIPSO (https://eosweb.larc.nasa.gov/) instrument scientific teams at NASA for the provision of satellite data, which is available online and formed the central database in the present work.

Conflicts of Interest: The authors declare no conflict of interest.

\section{References}

1. Wylie, D.P.; Jackson, D.L.; Menzel, W.P.; Bates, J.J. Trends in Global Cloud Cover in Two Decades of HIRS Observations. J. Clim. 2005, 18, 3021-3031. [CrossRef]

2. Mülmenstädt, J.; Sourdeval, O.; Delanoe, J.; Quaas, J. Frequency of occurrence of rain from liquid-, mixed-, and ice-phase clouds derived from A-Train satellite retrievals. Geophys. Res. Lett. 2015, 42, 6502-6509. [CrossRef]

3. Hong, Y.; Liu, G.; Li, J.-L.F. Assessing the Radiative Effects of Global Ice Clouds Based on CloudSat and CALIPSO Measurements. J. Clim. 2016, 29, 7651-7674. [CrossRef]

4. Lee, J.; Yang, P.; Dessler, A.; Gao, B.-C.; Platnick, S. Distribution and Radiative Forcing of Tropical Thin Cirrus Clouds. J. Atmos. Sci. 2009, 66, 3721-3731. [CrossRef]

5. Baran, A.J. From the single-scattering properties of ice crystals to climate prediction: A way forward. Atmos. Res. 2012, 112, 45-69. [CrossRef]

6. Khatri, P.; Iwabuchi, H.; Saito, M. Vertical Profiles of Ice Cloud Microphysical Properties and Their Impacts on Cloud Retrieval Using Thermal Infrared Measurements. J. Geophys. Res. Atmos. 2018, 123, 5301-5319. [CrossRef]

7. Waliser, D.E.; Li, J.-L.F.; Woods, C.P.; Austin, R.T.; Bacmeister, J.; Chern, J.; Del Genio, A.; Jiang, J.H.; Kuang, Z.; Meng, H.; et al. Cloud ice: A climate model challenge with signs and expectations of progress. J. Geophys. Res. Space Phys. 2009, 114, 21. [CrossRef]

8. Cesana, G.; Chepfer, H. Evaluation of the cloud thermodynamic phase in a climate model using CALIPSO-GOCCP. J. Geophys. Res. Atmos. 2013, 118, 7922-7937. [CrossRef]

9. Cesana, G.; Waliser, D.E.; Jiang, X.; Li, J.F. Multimodel evaluation of cloud phase transition using satellite and reanalysis data. J. Geophys. Res. Atmos. 2015, 120,7871-7892. [CrossRef]

10. Tan, I.; Storelvmo, T.; Choi, Y.-S. Spaceborne lidar observations of the ice-nucleating potential of dust, polluted dust, and smoke aerosols in mixed-phase clouds. J. Geophys. Res. Atmos. 2014, 119, 6653-6665. [CrossRef]

11. Eliasson, S.; Buehler, S.A.; Milz, M.; Eriksson, P.; John, V.O. Assessing observed and modelled spatial distributions of ice water path using satellite data. Atmos. Chem. Phys. Discuss. 2011, 11, 375-391. [CrossRef]

12. Hong, Y.; Liu, G. The Characteristics of Ice Cloud Properties Derived from CloudSat and CALIPSO Measurements. J. Clim. 2015, 28, 3880-3901. [CrossRef]

13. King, M.D.; Platnick, S.; Menzel, W.P.; Ackerman, S.A.; Hubanks, P.A. Spatial and Temporal Distribution of Clouds Observed by MODIS Onboard the Terra and Aqua Satellites. IEEE Trans. Geosci. Remote. Sens. 2013, 51, 3826-3852. [CrossRef]

14. Holz, R.; Ackerman, S.A.; Nagle, F.W.; Frey, R.; Dutcher, S.; Kuehn, R.E.; Vaughan, M.A.; Baum, B. Global Moderate Resolution Imaging Spectroradiometer (MODIS) cloud detection and height evaluation using CALIOP. J. Geophys. Res. Space Phys. 2008, 113. [CrossRef] 
15. Sun, W.; Videen, G.; Kato, S.; Lin, B.; Lukashin, C.; Hu, Y. A study of subvisual clouds and their radiation effect with a synergy of CERES, MODIS, CALIPSO, and AIRS data. J. Geophys. Res. Atmos. 2011, 116, D22207. [CrossRef]

16. Berry, E.; Mace, G.G.; Gettelman, A. Using A-Train Observations to Evaluate Cloud Occurrence and Radiative Effects in the Community Atmosphere Model during the Southeast Asia Summer Monsoon. J. Clim. 2019, 32, 4145-4165. [CrossRef]

17. Lauer, A.; Hamilton, K. Simulating Clouds with Global Climate Models: A Comparison of CMIP5 Results with CMIP3 and Satellite Data. J. Clim. 2013, 26, 3823-3845. [CrossRef]

18. Berry, E.; Mace, G.G. Cloud properties and radiative effects of the Asian summer monsoon derived from A-Train data. J. Geophys. Res. Atmos. 2014, 119, 9492-9508. [CrossRef]

19. Tsushima, Y.; Ringer, M.A.; Webb, M.J.; Williams, K.D. Quantitative evaluation of the seasonal variations in climate model cloud regimes. Clim. Dyn. 2012, 41, 2679-2696. [CrossRef]

20. Liu, Z.; Vaughan, M.A.; Winker, D.; Kittaka, C.; Getzewich, B.; Kuehn, R.; Omar, A.; Powell, K.; Trepte, C.; Hostetler, C. The CALIPSO Lidar Cloud and Aerosol Discrimination: Version 2 Algorithm and Initial Assessment of Performance. J. Atmos. Ocean. Technol. 2009, 26, 1198-1213. [CrossRef]

21. Huang, L.; Jiang, J.; Wang, Z.; Su, H.; Deng, M.; Massie, S. Climatology of cloud water content associated with different cloud types observed by A-Train satellites. J. Geophys. Res. Atmos. 2015, 120, 4196-4212. [CrossRef]

22. Su, H.; Jiang, J.H.; Vane, D.G.; Stephens, G.L. Observed vertical structure of tropical oceanic clouds sorted in large-scale regimes. Geophys. Res. Lett. 2008, 35. [CrossRef]

23. Andersson, S.M.; Martinsson, B.G.; Vernier, J.-P.; Friberg, J.; Brenninkmeijer, C.A.M.; Hermann, M.; Van Velthoven, P.F.J.; Zahn, A. Significant radiative impact of volcanic aerosol in the lowermost stratosphere. Nat. Commun. 2015, 6, 7692. [CrossRef]

24. Zhao, B.; Gu, Y.; Liou, K.-N.; Wang, Y.; Liu, X.; Huang, L.; Jiang, J.; Su, H. Type-Dependent Responses of Ice Cloud Properties to Aerosols From Satellite Retrievals. Geophys. Res. Lett. 2018, 45, 3297-3306. [CrossRef] [PubMed]

25. Pan, H.; Bu, L.; Kumar, K.R.; Gao, H.; Huang, X.; Zhang, W. A new retrieval method for the ice water content of cirrus using data from the CloudSat and CALIPSO. J. Atmos. Solar-Terrestrial Phys. 2017, 161, 134-142. [CrossRef]

26. Huang, L.; Jiang, J.; Tackett, J.L.; Su, H.; Fu, R. Seasonal and diurnal variations of aerosol extinction profile and type distribution from CALIPSO 5-year observations. J. Geophys. Res. Atmos. 2013, 118, 4572-4596. [CrossRef]

27. Sassen, K.; Wang, Z. Classifying clouds around the globe with the CloudSat radar: 1-year of results. Geophys. Res. Lett. 2008, 35. [CrossRef]

28. Sassen, K.; Wang, Z.; Liu, D. Global distribution of cirrus clouds from CloudSat/Cloud-Aerosol Lidar and Infrared Pathfinder Satellite Observations (CALIPSO) measurements. J. Geophys. Res. Space Phys. 2008, 113. [CrossRef]

29. Lee, L.; Zhang, J.; Reid, J.S.; Yorks, J.E. Investigation of CATS aerosol products and application toward global diurnal variation of aerosols. Atmos. Chem. Phys. Discuss. 2019, 19, 12687-12707. [CrossRef]

30. Sassen, K.; Cho, B.S. Subvisual-Thin Cirrus Lidar Dataset for Satellite Verification and Climatological Research. J. Appl. Meteorol. 1992, 31, 1275-1285. [CrossRef]

31. Martins, E.; Noel, V.; Chepfer, H. Properties of cirrus and subvisible cirrus from nighttime Cloud-Aerosol Lidar with Orthogonal Polarization (CALIOP), related to atmospheric dynamics and water vapor. J. Geophys. Res. Space Phys. 2011, 116. [CrossRef]

32. Winker, D.M.; Hunt, W.H.; McGill, M.J. Initial performance assessment of CALIOP. Geophys. Res. Lett. 2007, 34, L19803. [CrossRef]

33. Winker, D.M.; Vaughan, M.A.; Omar, A.; Hu, Y.; Powell, K.A.; Liu, Z.; Hunt, W.H.; Young, S.A. Overview of the CALIPSO Mission and CALIOP Data Processing Algorithms. J. Atmos. Ocean. Technol. 2009, 26, 2310-2323. [CrossRef]

34. Powell, K.A.; Hostetler, C.A.; Vaughan, M.A.; Lee, K.-P.; Trepte, C.R.; Rogers, R.R.; Winker, D.M.; Liu, Z.; Kuehn, R.E.; Hunt, W.H.; et al. CALIPSO Lidar Calibration Algorithms. Part I: Nighttime 532-nm Parallel Channel and 532-nm Perpendicular Channel. J. Atmos. Ocean. Technol. 2009, 26, 2015-2033. [CrossRef]

35. Balmes, K.A.; Fu, Q.; Thorsen, T.J. Differences in Ice Cloud Optical Depth From CALIPSO and Ground-Based Raman Lidar at the ARM SGP and TWP Sites. J. Geophys. Res. Atmos. 2019, 124, 1755-1778. [CrossRef] 
36. Mace, G.G.; Zhang, Q.; Vaughan, M.; Marchand, R.; Stephens, G.; Trepte, C.; Winker, D. A description of hydrometeor layer occurrence statistics derived from the first year of merged Cloudsat and CALIPSO data. J. Geophys. Res. Space Phys. 2009, 114. [CrossRef]

37. Villanueva, D.; Heinold, B.; Seifert, P.; Deneke, H.; Radenz, M.; Tegen, I. The day-to-day co-variability between mineral dust and cloud glaciation: A proxy for heterogeneous freezing. Atmos. Chem. Phys. Discuss. 2020, 20, 2177-2199. [CrossRef]

38. Sourdeval, O.; Gryspeerdt, E.; Kraemer, M.; Goren, T.; Delanoë, J.; Afchine, A.; Hemmer, F.; Quaas, J. Ice crystal number concentration estimates from lidar-radar satellite remote sensing-Part 1: Method and evaluation. Atmos. Chem. Phys. Discuss. 2018, 18, 14327-14350. [CrossRef]

Publisher's Note: MDPI stays neutral with regard to jurisdictional claims in published maps and institutional affiliations.

(C) 2020 by the authors. Licensee MDPI, Basel, Switzerland. This article is an open access article distributed under the terms and conditions of the Creative Commons Attribution (CC BY) license (http://creativecommons.org/licenses/by/4.0/). 